\title{
UMA PROPOSTA DE ATIVIDADE DO TIPO "HANDS-ON" REALIZADA NA DISCIPLINA INTRODUÇÃO À ENGENHARIA MECÂNICA DE FORMA REMOTA
}

DOI: 10.37702/2175-957X.COBENGE.2021.3733

Victória da Silva Braga - victoriabraga@id.uff.br

Universidade Federal Fluminense

Avenida Professor João Brasil 150

24130-082 - Niterói - RJ

Rodrigo Pereira da Silva Lessa - rpslessa@hotmail.com

UFF

rua Presidente Pedreira 153

24210-470 - Niterói - RJ

Fabiana Rodrigues Leta - fabianaleta@id.uff.br

Universidade Federal Fluminense

R. Voluntários da Pátria 100

22270-010 - Rio de Janeiro - RJ

Resumo: No ano de 2020, o mundo foi afetado pela pandemia do Covid-19 e, por consequência disso, as universidades brasileiras adotaram o ensino remoto. Isso afetou diretamente os alunos e como uma forma de fazê-los se sentirem acolhidos, estimular o trabalho em grupo com os colegas de curso, incentivar a pesquisa científica e introduzir aplicações da Engenharia Mecânica, foi criado um projeto com as turmas de Introdução à Engenharia Mecânica, do primeiro e segundo semestre de 2020, da Universidade Federal Fluminense, Niterói- RJ. Esse projeto "hands on" consiste em estimular os estudantes de $1^{\circ}$ período, divididos em grupos, a estudar como a física está aplicada no cotidiano e realizar um experimento caseiro utilizando apenas materiais recicláveis ou itens de fácil acesso. 0 experimento da primeira turma de 2020 se tratava em desenvolver protótipos de automóveis para ultrapassar rampas com propulsão mecânica e o da segunda turma, em desenvolver barcos transportadores de água com corante com propulsão eólica.

Palavras-chave: Ensino Remoto, Ciência, Pesquisa Científica,Engenharia 


\section{(C. COBENGE e IV Simpósio Internacional de Educação em Engenharia

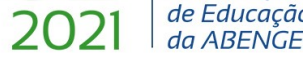 28 a 30 de SETEMBRO

Mecânica, Calouros, Experimentos caseiros 


\section{UMA PROPOSTA DE ATIVIDADE DO TIPO “HANDS-ON" REALIZADA NA DISCIPLINA INTRODUÇÃO À ENGENHARIA MECÂNICA DE FORMA REMOTA}

\section{INTRODUÇÃO}

O ensino remoto dificulta o desenvolvimento dos conteúdos da disciplina Introdução à Engenharia Mecânica, do curso de Engenharia Mecânica da Universidade Federal Fluminense de Niterói-RJ, onde visa-se dentre os seus objetivos apresentar conceitos de engenharia mecânica sob a ótica de projetos inovadores, já que os alunos, em sua maioria, são alunos calouros que ainda não possuem qualquer vivência dentro da universidade. Além da aula virtual ser um ambiente novo, a universidade também é, para estes alunos. As novas tecnologias podem oferecer desafios adicionais, como os alunos não saberem como acessar as aulas síncronas e ainda há a possibilidade de chegar à faculdade sem conhecer nenhum de seus colegas de curso.

Segundo uma pesquisa (G1,02/2021), cerca de $76 \%$ dos universitários brasileiros afirmaram ter sua saúde mental afetada durante a pandemia. Nesse contexto, os objetivos da disciplina são: trazer, de forma inovadora, o aluno para o ambiente da universidade, ainda que virtualmente; estimular o networking e o trabalho em grupo; incentivar a pesquisa científica, e, principalmente, introduzir aplicações da Engenharia Mecânica através da fabricação de modelagens 3D (disciplina não prevista na grade curricular obrigatória do curso) e de protótipos com materiais recicláveis e de fácil acesso (visando não incentivar os alunos a gastarem dinheiro e precisarem sair de casa durante a situação atípica atual de a pandemia).

Para atender a esses objetivos, durante os dois semestres de aula de ensino remoto (2020), os alunos de primeiro período foram estimulados a estudar, em grupos de até quatro integrantes, como a Física está aplicada em atividades do cotidiano através do livro "How Things Work - The Physics of Everyday Life" (BLOOMFIELD, 2005) e concluir um desafio proposto. O desafio da primeira turma de 2020 consistiu em desenvolver protótipos recicláveis de veículos para ultrapassar rampas com propulsão mecânica e o da segunda turma, em desenvolver barcos transportadores de água com corante com propulsão eólica.

Inspirados nessa perspectiva e considerando as particularidades de uma disciplina ministrada para calouros em um momento crítico de pandemia, apresenta-se neste artigo uma das atividades desenvolvidas na disciplina Introdução à Engenharia Mecânica em 2020.

\section{METODOLOGIA}

Primeiramente, os alunos da turma de Introdução à Engenharia Mecânica, disciplina do $1^{\circ}$ período da Universidade Federal Fluminense, foram apresentados aos conceitos físicos que poderiam ser utilizados no trabalho proposto: as três leis de Newton, trabalho, energia potencial, empuxo, princípio de Pascal, equação de Bernoulli etc. Nessa etapa, também foram apresentadas situações cotidianas, onde esses conceitos estão aplicados, usando como referencial Bloomfield (2005) e Walker (2008). 
Em seguida, foram formados grupos de até 4 alunos. Este foram provocados a desenvolver protótipos que atendessem aos desafios propostos e analisar o comportamento dos seus respectivos modelos ao serem expostos às situações estabelecidas.

A fundamentação desta proposta é pautada na prototipação. Esta é uma das etapas do Design Thinking, que consiste em "uma metodologia que aplica ferramentas do Design para solucionar problemas complexos, por meio do raciocínio associativo e do pensamento analítico, centralizando as pessoas e suas necessidades no processo" (CARVALHO, 2020) - sendo, portanto, de grande importância para a realização de projetos. Uma definição para o termo protótipo seria "a tangebilização de uma ideia, a passagem do abstrato para o físico de forma a representar a realidade - mesmo que simplificada - e proporcionar validações" (VIANNA,2012, p122). Através do seu desenvolvimento os alunos trabalham o conceito de "hands-on" em projetos de caráter prático.

Além disso, foi pedido que o protótipo fosse desenvolvido somente com materiais recicláveis ou de fácil acesso para não dificultar muito a elaboração do experimento, visto que no momento todos encontravam-se em um período de isolamento social devido à pandemia do Covid-19. Essa restrição dos materiais gera, também, impactos positivos, pois no século XXI, tornou-se imprescindível a conscientização ambiental, por parte de todos, e estimula ainda mais a criatividade dos alunos (JORNALZONASUL, 09/2020).

A exposição dos resultados de ambas as turmas foi feita por meio de relatórios escritos em formato de artigo acadêmico, apresentações de até 10 minutos na plataforma Google Meet e vídeos, mostrando os testes feitos com os protótipos. Essa primeira experiência com os relatórios em formato de artigo acadêmico e as apresentações tornase importante para a vida acadêmica e profissional dos estudantes, uma vez que "a escrita abre as portas para ser o caminho de contribuição com a solução de esclarecimentos individuais e coletivos e como suporte para a inclusão histórico-social no mundo investigativo." (BIANCHETTI, 2008, p.262).

Para promover um saudável clima de competitividade entre os alunos, os alunos dos três grupos com maior pontuação geral receberam certificados. Era esperado, também, melhorar a interatividade entre os alunos da turma, mesmo no ensino remoto, onde não há um ambiente físico para sua realização. Nesse contexto, foi possível estimular o ambiente social, mesmo que de forma remota, considerando que este "pode favorecer a aproximação, a interação e o diálogo" (RANGEL, 2005), que são importantes para uma construção coletiva do conhecimento.

\subsection{Carro a propulsão (desafio 2020.1)}

A proposta do desafio de 2020.1 consistiu em: construção de um carrinho (não pode ser movido a propulsão elétrica), com materiais que tivessem em casa, que deveria se mover por $50 \mathrm{~cm}$ e, em seguida, subir rampas de $30^{\circ}, 45^{\circ}$ e $60^{\circ}$, andando a maior distância possível na rampa.

Os critérios de avaliação foram:

- Entrega do vídeo no prazo estabelecido;

- Entrega do relatório no prazo estabelecido;

- Estética do carrinho;

- Conseguir passar da rampa de $30^{\circ}$, obedecendo todos os pré-requisitos estabelecidos;

- Conseguir passar da rampa de $45^{\circ}$, obedecendo todos os pré-requisitos estabelecidos; 
- Conseguir passar da rampa de $60^{\circ}$, obedecendo todos os pré-requisitos estabelecidos;

- Distância máxima percorrida na rampa;

- Tempo máximo em movimento;

- Apresentação.

\subsection{Transporte de água com corante através de barco a vela (desafio 2020.2)}

A proposta do desafio de 2020.2 consistiu em: prototipagem com materiais que tivessem em casa de barcos a vela para fazer o transporte do maior volume de óleo (muitos alunos utilizaram água com corante para evitar acidentes com óleo) possível em um reservatório com água. Esse reservatório poderia ser uma pia, tanque, piscina ou algo similar. O experimento deveria ser gravado e mostrar que o barco tinha capacidade de se movimentar, sem afundar, com o carregamento do fluido.

Os critérios de avaliação foram:

- Entrega do vídeo no prazo estabelecido;

- Entrega do relatório no prazo estabelecido;

- Estética do barco a vela;

- Volume máximo de fluido transportado;

- Apresentação.

\section{RESULTADOS}

Os grupos apresentaram soluções criativas para os desafios propostos. Foi observada a diversidade de soluções, considerando: os materiais usados para manufaturar os protótipos (lata de refrigerante, lata de bala, ratoeira, pilhas, CDs, garrafas pet, tampas de garrafa PET, madeiras, entre outros), o tipo de propulsão dos carros (elástica, através de água, de bicarbonato de sódio e vinagre), para produção das rampas (papelão, madeira, livros), das velas dos barcos (sacolas de plástico, garrafas pet, papel, etc) e o uso de diferentes reservatórios para o teste dos barcos (baldes, banheiras, piscinas).

É possível destacar no desafio do carro o protótipo produzido a partir de ratoeira e CD que teve o design inovador, porém só conseguiu atravessar as rampas de $30^{\circ}$ e $45^{\circ}$ propostas no desafio (FIG. 1). Já o protótipo mais simples feito com garrafa PET conseguiu obter êxito em todas as etapas do desafio (FIG. 2).

No desafio do barco destacaram-se dois protótipos que conseguiram transportar 4 litros de água colorida cada. Ambos com um design diferente, um feito de madeira encapada e o outro de garrafa PET (FIG. 3 e FIG. 4, respectivamente). 
Figura 1: Carro feito com ratoeira e CD.

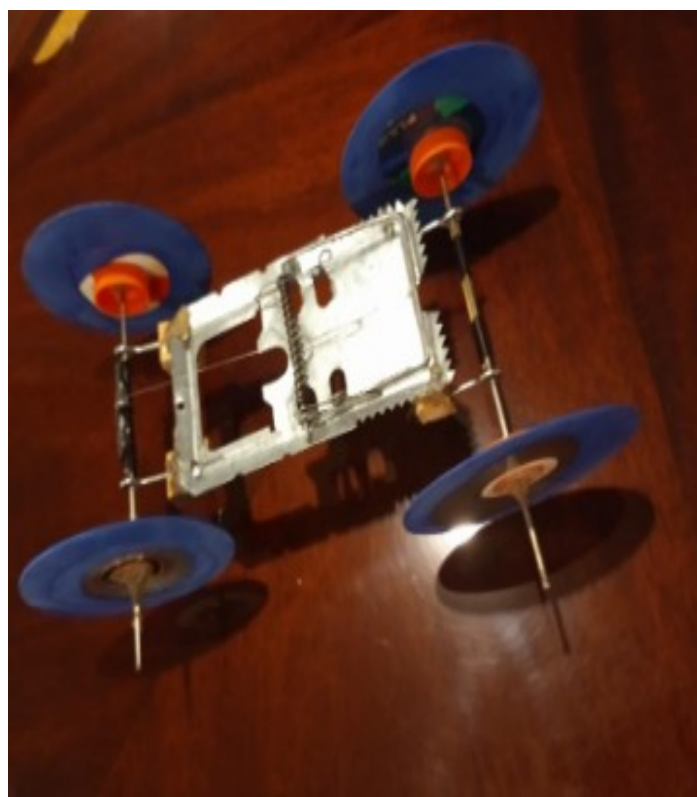

Fonte: alunos da disciplina

Figura 2: Carro feito de garrafa PET.

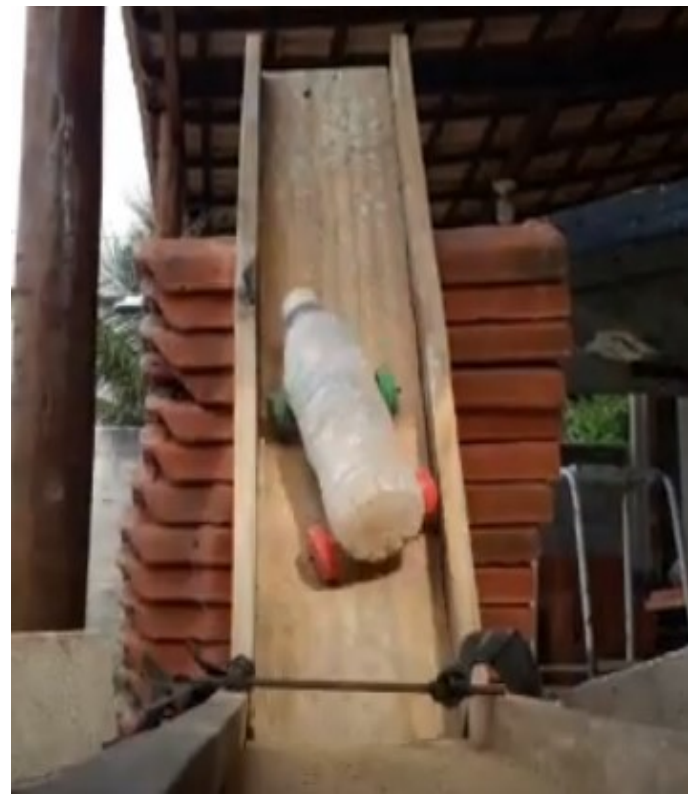

Fonte: alunos da disciplina 
Figura 3: Barco feito com madeira.

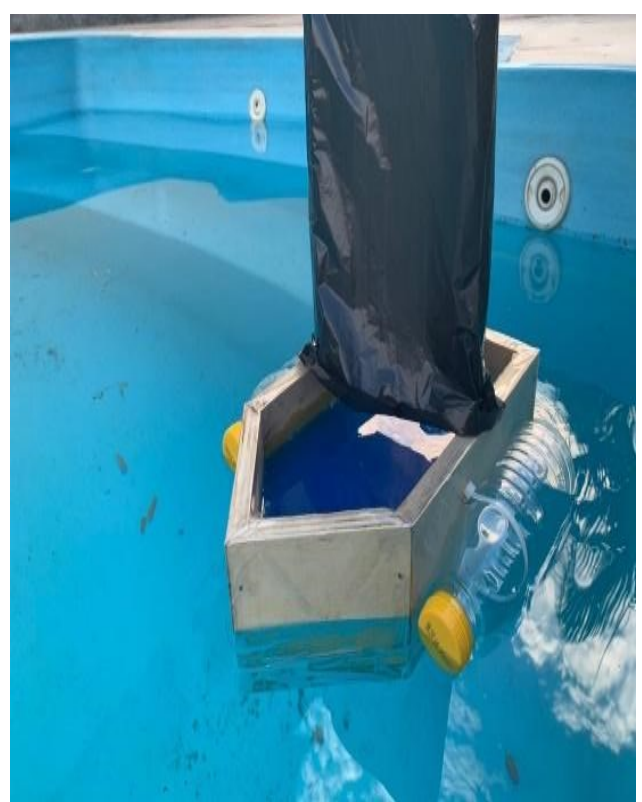

Fonte: alunos da disciplina

Figura 4: Barco feito de garrafa PET

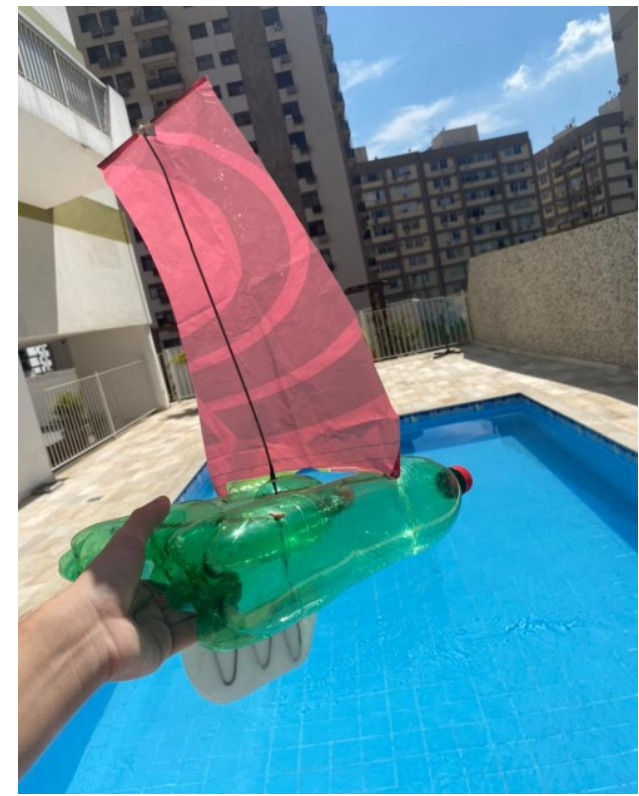

Fonte: alunos da disciplina

Todos os discentes apresentaram um embasamento teórico antes de exibirem seus modelos. Apesar do clima de competição, os grupos nos dois semestres vibraram e parabenizaram uns aos outros pelos projetos apresentados. Os alunos também exibiram maior motivação para continuar a assistir às aulas remotamente após terem um contato 
mais focado com a Engenharia Mecânica através do desenvolvimento do protótipo e realização dos desafios. Além disso, foi visível o aumento na interação entre eles tanto nas aulas quanto no grupo da turma no WhatsApp. O principal relato dos alunos foi que eles não esperavam este tipo de atividade e acharam um grande desafio trabalharem em grupo à distância, mas que ao final se sentiram realizados com o resultado.

Ao final do trabalho, foi pedido aos alunos que fizessem um comentário sobre sua experiência e alguns desses comentários foram:

- "Achei muito interessante! Agregou-se muito conhecimento que vou levar para a vida profissional.";

- "A minha interação com os colegas de faculdade foi maior, experimentei novos desafios e me senti mais familiarizada com a engenharia mecânica.";

- "Gostei muito! Motivou ainda mais a seguir a carreira de engenheiro.";

- "Foi um desafio muito interessante, pois tivemos que estudar sobre vários assuntos como a ação do vento na vela e as leis da física que agiam no experimento.".

\section{CONCLUSÔES}

Tendo em vista os aspectos observados, é possível afirmar que os desafios apresentados foram fonte de motivação e fomento da criatividade nos alunos do primeiro período. Alguns alunos se sentem desmotivados pelo impacto do primeiro período de Engenharia na vida acadêmica e a disciplina de Introdução à Engenharia Mecânica é o que introduz os mesmos ao que a universidade e o curso podem oferecer, auxiliando-o a aproveitá-la da melhor forma possível.

Além disso, percebe-se que algumas competências importantes para futuros trabalhos, seja no meio acadêmico ou até mesmo no mercado de trabalho, foram trabalhadas e, dentre elas, destacam-se: a própria criatividade, citada anteriormente, durante a elaboração do experimento; o estudo do conteúdo teórico, que seria mostrado somente em períodos posteriores, mas que era necessário para dar um embasamento para o projeto; o preparo para a escrita científica, imprescindível para a realização de artigos científicos e outros trabalhos acadêmicos; o treino da oratória e preparo de slides e vídeos para a apresentação do trabalho, muito recorrentes tanto na vida acadêmica quanto na profissional. Contudo, não se pode esquecer do evidente aumento da interatividade entre os alunos, o que havia sido muito comprometido com a pandemia do Covid-19. A realização do projeto trouxe um desafio adicional aos alunos, que foi a integração do grupo remotamente, especialmente pelo fato de não se conhecerem antes de iniciarem o curso.

Cabe destacar que o relato dos alunos após apresentarem o projeto foi extremamente positivo, todos se sentiram desafiados e realizados, mesmo quando os protótipos não tinham o resultado esperado. O fato de "colocarem a mão na massa", embora inicialmente tenha sido fonte de preocupação, por não saberem como iriam projetar e realizar a proposta em grupo de forma distanciada, ao final foi motivo de grande satisfação para todos.

Com os resultados positivos observados, é preciso ressaltar que o projeto não termina com a turma do segundo semestre de 2020. Os estudos baseados do livro "How Things Work - The Physics of Everyday Life" ainda perduram e para as próximas turmas que ingressarão no curso, haverá novos desafios, igualmente interessantes, seguindo a mesma metodologia. 


\section{Agradecimentos}

Por todo o esforço e dedicação ao desenvolver os desafios, agradecemos os alunos do primeiro e segundo semestre da disciplina de Introdução à Engenharia Mecânica, do curso de Engenharia Mecânica, da Universidade Federal Fluminense de Niterói-RJ.

Pelo suporte ao projeto, agradecemos ao MEC-SESu e à Universidade Federal Fluminense de Niterói-RJ.

\section{REFERÊNCIAS}

BIANCHETTI, Lucidio, et al. (Orgs.). A Trama do Conhecimento: teoria, método e escrita em ciência e pesquisa. Campinas: Papirus, 2008.

BLOOMFIELD, Louis Al. How Things Work - The Physics of Every Day Life. $5^{\circ}$ ed. Estados Unidos: Wiley, 2005.

CARVALHO, Natali Silva. O conhecimento do modelo de design thinking como indutor na inovação na sala de aula: um estudo com o corpo docente do curso de ciências contábeis do UNIFACIG.2020. Trabalho de Conclusão de Curso - Curso de Ciências Contábeis. UNIFACIG, 2020. Disponível em:

<http://pensaracademico.unifacig.edu.br/index.php/repositoriotcc/article/view/2523>. Acesso em: 24/04/2021.

JORNALZONASUL. Reciclagem estimula criatividade. Disponível em:

https://jornalzonasul.com.br/reciclagem-estimula-criatividade/. Acesso em: 23/04/2021.

OLIVEIRA, Elida; G1. Brasil tem maior índice de universitários que declaram ter saúde mental afetada na pandemia. Disponível em:

https://g1.globo.com/educacao/noticia/2021/02/26/brasil-tem-maior-indice-deuniversitarios-que-declaram-ter-saude-mental-afetada-na-pandemia-diz-pesquisa.ghtml. Acesso em: 23/04/2021.

RANGEL, Mary. Métodos de ensino para a aprendizagem e a dinamização das aulas. São Paulo: Papirus, 2005.

VIANNA, Maurício et al. Design Thinking: Inovação em Negócios. Rio de Janeiro: MJV Press, 2012.

WALKER, Jearl. O Circo Voador da Física. $2^{\circ}$ ed. Brasil: LTC, 2008.

\section{A "HANDS-ON" PROPOSAL ACTIVITY REMOTELY HELD IN THE DISCIPLINE INTRODUCTION TO MECHANICAL ENGINEERING}

Abstract: In 2020, the world was affected by the Covid-19 pandemic and, as a result, Brazilian universities adopted remote education. This directly affected students and as a way to make them feel welcomed, encourage group work with fellow students, encourage scientific research and introduce applications of Mechanical Engineering, a project was created with the Introduction to Mechanical Engineering class, from the first and second 
semester of 2020, from Universidade Federal Fluminense, Niterói-RJ. This hands-on project consists of stimulating 1st term students, divided into groups, to study how physics is applied in their daily lives and to carry out a homemade experiment using only recyclable materials or easily accessible items. The experiment of the first class of 2020 was to develop prototypes of automobiles to overcome ramps with mechanical propulsion and that of the second class, to develop boats carrying water with dye with wind propulsion.

Keywords: Remote Education, Scientific Research, Mechanical Engineering, 1st Term Students, Homemade Experiment. 